\title{
Distopia e vida Cotidiana: o imaginário de Black Mirror, a crise do humanismo e a midiatização da existência
}

\author{
Dystopia and daily life: The imagination of Black Mirror, the crisis of \\ humanism and the mediatization of the existence
}

\section{Dystopie et vie quotidienne : l'imaginaire de Black Mirror, la crise de l'humanisme et la médiatisation de l'existence}

\section{Vincenzo Susca}

É professor de Sociologia do Imaginário na Universidade Paul-Valéry (Montpellier, França). Pesquisador no Centro de Estudos sobre o Atual e o Cotidiano (Sorbonne) e no McLuhan Fellow na Universidade de Toronto. É também diretor editorial dos Cahiers européens de l'imaginaire. Publicou no Brasil: Pornocultura (2017, Ed. Sulina) e As Afinidades conectivas (2019, Ed. Sulina).

\section{Tradução}

\section{Lucas Murari}

Doutor em Comunicação e Cultura pela Escola de Comunicação da Universidade Federal do Rio de Janeiro, com período sanduíche na Université Sorbonne Nouvelle - Paris 3 (bolsa CAPES). É editor-executivo da Revista Eco-Pós. Atualmente realiza estágio de pós-doutorado na ECO/UFRJ sobre cinema de vanguarda no Brasil (PNPD/CAPES).

\section{Alexandre Kenichi Gouin}

Mestre em Engenharia de Produção pela École Centrale Paris. Trabalha como pesquisador de imagens para produções artísticas e audiovisuais. É editor da Revista Eco-Pós. Atualmente realiza Mestrado em Comunicação e Cultura pela Escola de Comunicação da Universidade Federal do Rio de Janeiro, com pesquisa sobre a montagem de imagens de arquivo no cinema experimental. 


\section{RESUMO}

Será que o "espelho da mídia" rompeu (talvez traísse sua "missão") ou se manifestou de forma coerente com suas premissas? A série Black Mirror é um estudo de caso exemplar que possibilita analisar questões cruciais sobre a sociedade contemporânea e que mergulha o público em seu abismo mais sombrio e mórbido. A sociedade do futuro ali descrita, com premonições lúgubres, lúcidas e visionárias, expressa de maneira paroxística o que já vivemos todos os dias. É preciso reconhecer que a distopia é constantemente presente nas nossas vidas diárias. Black Mirror é uma ficção científica "realista": é um espetáculo, um museu, uma prisão, uma obra de arte e um videogame interativo sem interrupção entre o exterior e o interior, o eu e o outro, o orgânico e o inorgânico. Em certo sentido, pode-se dizer que é o mundo em que vivemos, onde estamos todos sujeitos à vigilância generalizada e intangível, quando a tecnologia, os algoritmos e as redes sociais prevalecem sobre os indivíduos, anulando em grande medida a sua autonomia.

PALAVRAS-CHAVE: Comunicação; Distopia; Imaginário; Cotidiano; Pós-humanismo.

\section{ABSTRACT}

Has the media mirror shattered, betrayed its mission, or manifested itself in a manner consistent with its premises? Black Mirror is the text par excellence to examine in order to study this crucial question. Even more, it hurls us into its darkest and most morbid abysses. The society of the future described here with dismal, lucid and visionary premonitions expresses in a paroxysmal way what we are already experiencing on our skin. Dystopia at the heart of our daily life. It's realistic, very real science fiction: more real than reality. Black Mirror is a spectacle, a museum, a prison, a work of art and an interactive video game without discontinuity between the exterior and the interior, the self and the other in itself, the organic and the inorganic - it is the world we live in, where we are all subject to widespread and intangible surveillance, when technology, algorithms and social media take precedence over individuals, thus nullifying their autonomy. KEYWORDS: dystopia, imagination, everyday life, post-humanism.

\section{RÉSUMÉ}

Le «miroir médiatique» a-t-il brisé (peut-être trahi sa «mission») ou s'est-il manifesté de manière cohérente avec ses prémisses ? La série Black Mirror est une étude de cas exemplaire qui permet d'analyser des questions cruciales sur la société contemporaine et qui plonge le public dans ses abysses les plus sombres et les plus morbides. La société du futur décrite ici, avec des prémonitions lugubres, lucides et visionnaires, exprime de manière paroxystique ce que nous vivons déjà tous les jours. Nous devons reconnaître que la dystopie est constamment présente dans nos vies quotidiennes. Black Mirror est une science-fiction «réaliste»: est un spectacle,

Dossiê A Música e suas Determinações Materiais - https://revistaecopos.eco.ufrj.br/ 
un musée, une prison, une œuvre d'art et un jeu vidéo interactif sans interruption entre l'extérieur et l'intérieur, le moi et l'autre, le organique et inorganique. D'une certaine manière, on peut dire que c'est le monde dans lequel nous vivons, où nous sommes tous soumis à une surveillance généralisée et intangible, lorsque la technologie, les algorithmes et les réseaux sociaux prévalent sur les individus, annulant dans une large mesure leur autonomie.

MOTS-CLES: Communication; Dystopie; Imaginaire; La vie quotidienne; Posthumanisme.

As mídias sempre foram sistemas complexos e controversos. Das cavernas de Lascaux às redes digitais, das tábuas de argila sumérias às telas, elas constituem ao mesmo tempo a paisagem e a linguagem do ser humano: o território simbólico em que habitamos e a voz por meio da qual nos expressamos. Segundo os relatos provenientes de muitos campos disciplinares, onde se destacam os nomes de Martin Heidegger, Edgar Morin e Marshall McLuhan¹, não são ferramentas neutras, mas dispositivos que, enquanto os desenvolvemos, distribuímos e consumimos, por sua vez, nos moldam. A história ensina que nos tornamos efetivamente as criaturas dos sistemas técnicos e de comunicação que engendramos²: a relação que mantemos com eles não responde a um princípio monocausal e unidirecional, mas pelo contrário, a uma dinâmica baseada em uma constante reversibilidade, um vaivém,

\footnotetext{
1 Para mais detalhes, ver HEIDEGGER, M. Acheminement vers la parole. Paris: Gallimard, 1976; MCLUHAN, M. Os meios de comunicação como extensão do homem. São Paulo: Editora Cultrix, 1969; The Gutenberg Galaxy. The making of typographic man. Toronto: University of Toronto Press, 1966 ; MORIN, E. L'esprit du temps. Paris: Éditions Grasset, 1962.

${ }^{2}$ KERCHOVE, D. La peau de la culture. Montréal: Éditions Liber, 2020 ; INNIS, H. A. Empire and Communications. Toronto: Dundurn, 2007 ; MATTELART, A. La Communication-monde. Paris: La Découverte, 1999.
}

Dossiê A Música e suas Determinações Materiais - https://revistaecopos.eco.ufrj.br/ 
ou para retomar uma expressão querida à Gilbert Durand, uma jornada antropológica ${ }^{3}$.

O advento da cultura digital, a proliferação do sistema dos objetos, a difusão massiva das redes sociais, dos celulares, das telas e de todas as mediascapes acrescentam outros tantos elementos novos e reflexos ao retrato que acabamos de esboçar. Em particular, a midiatização do mundo e a globalização das mídias, com seu correlato de camadas de acidentes, confusões e convulsões que acarretam, impõem com urgência a definição das modalidades atuais da interação entre comunicação e cotidiano, objetos e sujeitos, técnica e cultura, mas também a apreensão de eventuais disfunções e da aparição de formas diferentes daquelas que conhecíamos e esperávamos. As mídias cumpriram as promessas de suas premissas ou, pelo contrário, traíram sua missão? Seu espelho se estilhaçou?

Se há um texto de antropologia cultural, de mediologia e de sociologia do imaginário que convém examinar para responder a essas questões fundamentais, é Black Mirror ${ }^{4}$. A série de televisão britânica escrita por Charlie Brooker para a Endemol nos mergulha nos abismos mais sombrios e mórbidos dessa problemática. Aliás, seu propósito se apresenta desde o início com sua logo, um espelho negro rachado, fio condutor de sua jornada diegética e potente metáfora para nossa condição tecnocultural. Premonições lúgubres, tão lúcidas quanto visionárias, representam a sociedade do futuro e transcrevem de maneira paroxística o que já estamos vivendo em nossa pele ${ }^{5}$ - ou sob nossa pele. A distopia no âmago de nossas

\footnotetext{
${ }^{3}$ DURAND, G. Les structures anthropologiques de l'imaginaire. Paris: Dunod, 1992.

${ }^{4}$ Essa é a hipótese que compartilhamos com vários pesquisadores no campo das ciências humanas e sociais, como Mario Tirino e Antonio Tramontana, que publicaram o livro I riflessi di Black Mirror. Glossario su immaginari, culture e media della società digitale. Rome: Rogas Edizioni, 2018. Em relação a análise crítica das questões levantadas, nos referimos ao livro de CIRUCCI, A.; VACKER, B. (orgs.). Black Mirror e Critical Media Theory. Lanham: Lexington Books, 2018.

5 Ver BENNATO, D. (.org). Black Mirror. Distopia e antropologia digitale. Catane: Villaggio Maori, 2018; CHIUSI, F. Dittature dell'istantaneo. Black Mirror e la nostra società iperconnessa. Turin: Codice Edizioni, 2014.
}

Dossiê A Música e suas Determinações Materiais - https://revistaecopos.eco.ufri.br/ 
vidas cotidianas. A série recorre a esse tipo de ficção científica realista, mais real do que a realidade, que faz as obras-primas. Uma ficção científica catastrófica, de acordo com a regra de ouro do gênero.

Que catástrofe é essa que nos diz respeito, onde somos todos objetos e sujeitos? E que margens de existência permanecem entre os aglomerados de ruínas espetaculares que nos cercam? Chegamos verdadeiramente, parafraseando Francis Fukuyama, ao fim da história ${ }^{6}$ ?

Após os horrores e os traumas da Segunda Guerra Mundial, acreditava-se que a humanidade pudesse reerguer-se e ressurgir das suas cinzas. Ora, a dobra surgida dessas circunstâncias e as feridas cavadas pelas bombas, pelos campos de concentração e todos os genocídios perpetrados pelas nações em conflito, se definem justamente por sua natureza irremediável. É o que sugere cada episódio de Black Mirror que investiga a atualidade desses eventos após o conflito. E mais, os efeitos deste último, tal qual uma espiral, só podem continuar se contorcendo e reavivando, com modulações inexploradas, a dor que eles carregam. Toda felicidade está ausente deste mundo se excluirmos raros lampejos de prazer ilusório. 0 que resta então da nossa humanidade? Da nossa experiência? Ainda existe um raio de esperança no futuro?

Na base da sociologia do imaginário ${ }^{7}$ e das mídias $^{8}$, levando em conta a ligação profunda na cultura contemporânea entre a vida cotidiana e as séries televisivas ${ }^{9}$,

\footnotetext{
6 FUKUYAMA, F. O fim da História e o último homem. Rio de Janeiro: Rocco, 1992.

7 LEGROS, P.; MONNEYRON, J-B.; TACUSSEL, P. Sociologie de l'imaginaire. Paris: Armand Colin, 2006; GRASSI, V. Introduction à la sociologie de l'imaginaire. Paris: Erès, 2005; XIBERRASM, M. Pratique de l'imaginaire, Laval: Pul, 2002.

8 ABRUZZESE, A.; MICONI, A. Zapping. Sociologia dell'esperienza televisiva. Naples: Liguori, 1999; MOORES, S. Interpreting audiences: the ethnography of media consumption. New York, Sage, 1993; WILLIAMS, R. Televisão: tecnologia e forma cultural. São Paulo: Boitempo; Belo Horizonte, 2016. 9 BRANCATO, S. Post-serialità. Per una sociologia delle tv-series. Dinamiche di trasformazione della fiction televisiva. Naples: Liguori, 2011. INNOCENTI, V.; PESCATORE, G. Le nuove forme della serialità televisiva. Storie, linguaggio, temi. Bologne: Archetipo Libri, 2008; ATTIMONELLI, C.; D’OTTAVIO, A. (.orgs). To be continued. I destini del corpo nei serial televisivi. Bari: CaratteriMobili, 2011. ROCCA, A.;
}

Dossiê A Música e suas Determinações Materiais - https://revistaecopos.eco.ufrj.br/ 
realizamos uma análise temática do conteúdo ${ }^{10}$, por uma metodologia qualitativa aplicada ao corpus natural ${ }^{11}$ de 19 episódios da série Black Mirror entre 2011 e 201912 com o objetivo de identificar a descrição e interpretação das formas simbólicas e coletivas, permitindo entender o novo equilíbrio entre a técnica, o poder e a sociedade estabelecidos na era da cultura digital ${ }^{13}$, dos algoritmos ${ }^{14}$ e das redes sociais ${ }^{15}$. Com efeito, se é verdade que o público de outrora é cada vez mais não apenas o conteúdo das novas mídias, mas também seu produtor ${ }^{16}$, esta série questiona até que ponto essa passagem crucial não se limitaria a integrar posteriormente, em relação às mídias de comunicação de massa, o corpo social, mas também constituiria um estágio de sua alienação, de sua reificação, de seu devir objeto e data à disposição da indústria cultural e das elites das quais é emanação.

MALAGAMBA, V.; SUSCA, V. (.orgs). Eroi del quotidiano. Figure della serialità televisiva. Milan: Bevivino, 2010; Sociétés, L'imaginaire des séries TV, n 128. Bruxelles: De Boeck, 2015.

${ }^{10}$ BARDIN, L. L'analyse de contenu. Paris: PUF, 2013.

11 GUILHAUMOU, J. Le corpus en analyse du discours: perspective historique. Corpus, N. 1, journals.openedition.org.

12 A partir desse material circunscrito, identificamos as informações que respondem às questões previamente definidas na pesquisa, destacando as regularidades, tendências e singularidades que nos permitem apreender a maneira pela qual esse objeto cultural revela imaginários compartilhados, referentes a um senso comum e uma atmosfera diária.

${ }^{13}$ CASTELLS, M. L'Ère de l'information. Vol. 1, La Société en réseaux. Paris: Fayard, 1998; SUSCA, V. Les Affinités connectives. Sociologie de la culture numérique. Paris : Cerf, 2016.

${ }^{14}$ CARDON, D. À quoi rêvent les algorithmes. Nos vies à l'heure des big data. Paris: Seuil, 2015; PIREDDU, M. Algoritmi. Il software culturale che regge le nostre vite. Bologne : Luca Sossella Editore, 2017; SADIN, É. La vie algorithmique: critique de la raison numérique. Paris : Éditions l’Échappée, 2015.

${ }^{15}$ CASILLI, A. Les liaisons numériques. Paris : Seuil, 2010 ; LOVINK, G. Networks without a Cause: A Critique of Social Media. Londres : Polity Press, 2012; MERCKLÉ, P. Sociologie des réseaux sociaux. Paris: La Découverte, 2004; SUSCA, V. Joie Tragique. Les formes élémentaires de la vie électronique. Paris: CNRS Éditions, 2011.

${ }^{16}$ JENKINS, H. Fans, bloggers, gamers. Exploring participatory culture. New York: New York Press, 2006.

Dossiê A Música e suas Determinações Materiais - https://revistaecopos.eco.ufrj.br/

ISSN $2175-8689$ - v. 23, n. 1, 2020

DOI: 10.29146/eco-pos.v23i1.27406 


\section{Uma série humana, demasiado humana...}

Durante séculos, nós, ocidentais, agimos sobre o tempo e o espaço a partir do sujeito, com objetivo de orquestrar o mundo segundo nossa vontade. No entanto, estamos doravante nos entregando a uma razão que nos precede e nos excede. Ela nos esquece, de certa forma, nos escapou das mãos e parece conspirar, com nossa cumplicidade, contra o homem moderno ${ }^{17}$. Black Mirror é nesse sentido o processo mais cruel intentado contra os tumultos pós-humanistas, pós-modernos e póshistóricos que estão sacudindo a ordem e as utopias cultivadas desde Florença do século XVI a Paris do século XIX. Seu método, como é o caso do personagem provocador em "Manda quem pode" ("Shut up and dance", S3E3, 2016), a espiã Marie em "Arkangel" ("Arkangel”, S4E2, 2017), ou o aparelho indiscreto que permite examinar as lembranças das pessoas em “Crocodilo" (“Crocodile”, S4E3, 2017), é o terrorismo psicológico. Cada episódio é uma bomba lançada contra nossa existência aparentemente normal, um dispositivo destinado a semear pânico e ansiedade no âmago da vida cotidiana e daquilo que é para nós o fluxo ordinário do tempo.

Assim como as vanguardas artísticas do século $\mathrm{XX}$, dos dadaístas aos situacionistas e futuristas, que se valeram do choque ${ }^{18}$ para despertar as consciências nubladas das massas, empurrando-as a se rebelar pela autonegação e para se reconhecerem alienados antes de se libertarem desse estado ${ }^{19}$, as obras, os produtos e as bombas-relógios que estamos tentando reconhecer aqui visam desestabilizar a linearidade de nossa experiência, desenterrar seu fundo escuro para nos assustar, num primeiro tempo, para em seguida desorientar a nós mesmos, para que possamos refazer nossos passos e redescobrir, com nossa autonomia individual, nossa humanidade.

17 HEIDEGGER, M. Carta sobre o Humanismo. São Paulo: Editora Moraes, 1991. 18 BENJAMIN, W. Aura e choc. Saggi sulla teoria dei media. Turin: Einaudi, 2012.

${ }^{19}$ ABRUZZESE, A. Forme estetiche e società di massa. Arte e pubblico. Venise: Marsilio, 2001; MICHELI, M. Le avanguardie artistiche del Novecento. Milan: Feltrinelli, 2014.

Dossiê A Música e suas Determinações Materiais - https://revistaecopos.eco.ufri.br/ 
Esse é o seu objetivo político, uma espécie de manifesto: interromper a celebração dos consumos e das comunicações, a orgia das redes sociais e a dança com as máquinas, salvar o indivíduo e devolver-lhe a soberania do eu, do mundo e da história. É de fato assim que se desenvolve um projeto humanista, talvez demasiado humano...

- Coloque-me de volta no meu corpo!

- É aqui que vive o seu verdadeiro eu. Mas ainda vamos dar a você um corpo artificial. Achamos que ajuda às vezes. Você está pronta?

- O que? Eu não entendo!

- Três, dois, um. É melhor assim?

- É o meu corpo ${ }^{20}$.

A situação cultural contemporânea não é apenas o resultado da maturação de processos inaugurados há séculos, como acabamos de indicar. Um dos aspectos que a tornam mais espinhosa e complexa é a reviravolta de tendência em relação às dinâmicas em prática até agora entre a realidade e as mídias. Assim como Baudrillard 21 antecipou em várias anotações do pensamento de McLuhan, chegamos a um estágio em que as mídias deixaram de ser uma extensão do ser humano, como era o caso no contexto analisado pelo gênio canadense, para se tornar seu pressuposto. Finalmente, depois de um longo período em que a tecnologia acolheu o ímpeto do humanismo ao desempenhar tendencialmente o papel de instrumento à sua disposição, nos encontramos hoje em outra configuração que se coloca enquanto sistema integral e inteligente de energias, algoritmos e dispositivos, tão poderosa que agora somos nós que derivamos dela. No entanto, o autor da famosa fórmula reveladora "o meio é a mensagem" não ignorava essa deriva: "incorporando continuamente tecnologias, relacionamo-nos a elas como

20 Texto original: "Put me back in my body! Hm. That's where real you lives. But what we will do though is we will give you a simulated body. We find that sometimes that helps. Are you ready? What? I don't understand! Three, and two, one. Hey. Better ? This is my body." (White Christmas).

${ }^{21}$ BAUDRILLARD, J. À l'ombre des majorités silencieuses ou la fin du social. Paris: Sens \& Tonka, 1997; Simulacros e Simulações. Lisboa: Relógio D’Água, 1992.

Dossiê A Música e suas Determinações Materiais - https://revistaecopos.eco.ufrj.br/ 
servomecanismos. Eis por que, para utilizar esses objetos-extensões-de-nósmesmos, devemos servi-los, como a ídolos ou religiões menores (McLuhan, 1969, p.64).

0 efeito perverso em questão, verdadeiro conteúdo das ansiedades e dos desconfortos evocados pela série inglesa, de "Hino Nacional" ("The National Anthem", E1S1, 2011) a "Black Museum" (E6S4, 2017) até "Natal" ("White Christimas”, Episódio Especial, 2014), tem múltiplas consequências radicais em nosso modo de ser humanos: implica um descentramento geral, um recuo, até uma submissão do indivíduo às paisagens midiáticas e a suas declinações. É provavelmente isso que mais nos perturba quando vemos, com tanta cobiça quanto temor, os diversos episódios da saga: o desaparecimento do sujeito moderno, como se cada morte, cada escravidão e cada humilhação dos protagonistas que se sucedem nas visões de Brooker prefigurassem de modo exacerbado e antecipado o nosso destino a curto prazo, pois algo neles sempre remete ao pântano em que já estamos atolados.

Como tal quadro pode nos enfeitiçar? Por que gostamos disso? Uma análise atenta sugere que uma fruição desse tipo não é simplesmente o produto das faculdades catárticas dos roteiros propostos pelos autores, nem da atração ancestral que a sombra e o mal têm sobre o público. Ao contrário, é sem dúvida mergulhando nessas visões lúgubres e refletindo sobre elas que conseguimos extrair prazer, na medida em que claramente detectamos o inevitável desconforto do indivíduo ocidental $^{22}$, não tanto em nome de vagas voluptuosidades sadomasoquistas, mas porque nos curvamos sob o peso de nossa história, renunciamos à esperança há muito tempo e acariciamos com júbilo secreto a ideia e a representação de sua ruína, de nossa ruína.

22 Sobre a crise do indivíduo moderno, nos referimos a MAFFESOLI, M. Le temps des tribus. Le déclin de l'individualisme dans les sociétés de masse. Paris: Méridiens-Klincksieck, 1988; Notes sur la postmodernité. Le lieu fait lien. Paris: Éditions du Félin, 2003.

Dossiê A Música e suas Determinações Materiais - https://revistaecopos.eco.ufrj.br/ 
Ao focalizar nos detalhes do dia a dia e no corpo, Black Mirror concretiza de maneira palpável e microfísica a catástrofe do nosso mundo, cujo desejo ressoa de forma mais ou menos latente no imaginário coletivo. É uma variante inédita da pulsão controversa que leva alguns de nós a ser atraídos pelo espetáculo mortífero do terrorismo ou pela devastação de cataclismas naturais e de outros acidentes fatais. Charlie Brooker mostra que a fonte do colapso não reside fora de nós, ou melhor, que esse exterior se infiltrou na superficialidade de nossa carne e nas profundezas de nosso inconsciente, que ele foi internalizado: a técnica. Essa constatação provoca em nós frustração, mas também ansiedade e um sentimento de impotência, uma percepção de alívio do $\operatorname{ser}^{23}$ - de acordo com a leveza que serve de ambiência emocional, de espírito, à nossa relação com os produtos da indústria cultural: uma espécie de alívio inspirado pelo fato de não sermos mais capazes de agir, criar, construir, acumular, mas apenas de ser agidos, consumidos e objetos de recriação/recreação ${ }^{24}$.

A ética, a estética e o público de Black Mirror exalam uma euforia niilista ao mesmo tempo imponente e viral. Uma vez superadas as épocas do desencantamento ${ }^{25}$ e do reencantamento ${ }^{26}$ do mundo, começa a operar uma espécie de encantamento do desencantamento, que reatualiza sob um nova forma a contemplação do declínio já experimentado pelos modernos, por exemplo, no fascínio exercido pelas gravuras de ruínas de Giovanni Battista Piranesi, as erupções vulcânicas e outros cataclismas representados em tons sublimes.

Yorkie: Então você não se sente mal?

[Kelly não sabe o que responder.]

Yorkie: Talvez você deva se sentir mal. Ou ao menos sentir alguma coisa.

23 VATTIMO, G. La società trasparente. Milano: Garzanti, 1989.

24 SUSCA, V. Récréations. Galaxies de l'imaginaire postmoderne. Paris: CNRS Éditions, Paris, 2009.

25 WEBER, Max. A ética protestante e o espírito do capitalismo. São Paulo: Companhia das Letras, 2004.

26 MAFFESOLI, M. Le réenchantement du monde. Paris: La Table Ronde, 2007.

Dossiê A Música e suas Determinações Materiais - https://revistaecopos.eco.ufrj.br/ 
[Ela se vira e sai. Kelly está prestes a chorar. Ela se vira para o espelho e observa seu reflexo. Ela bate no vidro com o punho, que se quebra. Kelly olha para sua mão. Não há sangue. Ela se olha no espelho, agora intacto novamente ${ }^{27}$

\section{A prisão aumentada}

Estamos todos em perigo enquanto nossa existência inflada e aumentada dilata de maneira implausível através de próteses, redes digitais, bancos de dados, algoritmos e tecnologias de conexão capazes de integrar nossa consciência ${ }^{28}$, de exacerbar nossas sensações e atingir nossos fantasmas. A mensagem mais black e paradoxal, na fronteira com o oximoro, que a série produzida pelo Netflix desde 2015 investe de maneira extrema, em sintonia com nosso tempo, reflete a etimologia do termo "existir", que vem do latim $\bar{e} x+$ sistentia: extrair a sua vida de outro, externo a si e ao eu. De fato, "a ek-sistência, segundo a grafia que ele sugere, consiste em uma ejeção, uma expulsão ou um exílio. 0 ek-sistente não é jogado fora de um lugar por uma vontade estrangeira: seu ser consiste inteiramente nesse serjogado" (Nancy, 2017, p.37)

“Versão de Testes" ("Playtest”, E2S3), "15 milhões de méritos" ("15 Million Merits", S1E2), "Urso Branco" ("White Bear”, S2E2) e outros ensaios da saga expõem da maneira mais obscena possível nossa dependência, assimétrica e desequilibrada em nosso detrimento, em relação à alteridade a qual estamos agora constantemente conectados. Se é verdade que o mundo está cada vez mais à nossa disposição, ao

\footnotetext{
${ }^{27}$ Texto original: Yorkie : So you don't feel bad [Kelly doesn't know what to say.] Yorkie: Maybe you should feel bad. Or at least feel something. [She turns and leaves. Kelly sighs. Turns and looks at herself in the mirror. Then she punches the mirror, hard. It splinters. Shatters. Kelly looks down at her hand. No blood. She looks at her reflection in the mirror, which is now unharmed.]

${ }^{28}$ Derrick de Kerckhove coloca a hipótese do advento de um inconsciente digital. KERCKHOVE, D. L'inconscio digitale. In: BUFFARDI, A.; KERCKHOVE, D. (.orgs). Il sapere digitale. Pensiero ipertestuale e conoscenza connettiva. Napoli: Liguori, 2011; PARISEAU-LEGAULT, J.; HOLMES, D.; MURRAY, S. Understanding human enhancement technologies through critical phenomenology. Irvine: Californie, Nursing Philosophy, 2018.
}

Dossiê A Música e suas Determinações Materiais - https://revistaecopos.eco.ufrj.br/ 
alcance de um clique ou de um simples pensamento, é porque cedemos à rede e seus derivados a parte mais substancial ${ }^{29}$ de nós mesmos, que nos entregamos a essas mãos invisíveis com uma inconsciência tendenciosa e generalizada. No fundo, os problemas induzidos pelo big data, a social profiling, os algoritmos e a inteligência artificial - em termos de subordinação, controle e manipulação do indivíduo remetem ao mesmo nó crucial: a aniquilação do sujeito autônomo e racional, do cogito ergo sum moderno ${ }^{30}$, a partir da violação de sua intimidade, da invasão de sua vida privada e em nome de outra coisa: de uma carne eletrônica tão embriagante quanto longe de cumprir as promessas de felicidade caras ao Ocidente.

No corpo a corpo generalizado que investe nosso cotidiano e o mundo em que vivemos, tornando este último um espaço denso e convulsivo marcado pela promiscuidade entre seus elementos - sujeitos e objetos, natureza e cultura, espírito e matéria -, a alteração que é corolário de qualquer relação íntima com a alteridade ${ }^{31}$ produz efeitos paroxísticos e corrói quase integralmente a armadura do eu forjada à custa de tantos esforços a partir do Renascimento até meados do século XX. Somos invadidos por nossos contatos, cercados pela miríade de pessoas e sistemas gananciosos que solicitam nossa atenção, ensurdecidos pelo barulho midiático, a ponto de perder todo vínculo com nosso centro de gravidade e, na confusão criada pela tatilidade e a proximidade típica do ritmo de vida eletrônico, perdemos também nosso "ponto de vista"32.

Da Rede às ruas, o intervalo espacial e temporal entre si e o outro, reduzido ao mínimo, revela uma condição social em muitos aspectos comparável a um tipo de

\footnotetext{
${ }^{29}$ FERRARIS, M. T'es où ? Ontologie du téléphone mobile. Paris: Albin Michel, 2011.

30 DESCARTES, René. Discurso do método. São Paulo: Abril Cultural, 1979.

31 JORON, P. La vie improductive. Georges Bataille et l'hétérologie sociologique. Montpellier: Presses Universitaires de la Méditerranée, 2009.

32 De maneira indicativa, D. de Kerckhov sugere que a cultura eletrônica faz a passagem do ponto de vista para o ponto de ser. In: KERCKHOVE, D.; MIRANDA, C. (.orgs). The point of being. New Castle Upon Tyne: Cambridge Scholars Publishing, 2014.
}

Dossiê A Música e suas Determinações Materiais - https://revistaecopos.eco.ufrj.br/ 
orgia permanente ${ }^{33}$, onde só desfrutamos a presença do outro entregando-nos a ele, como em uma espécie de prostituição sagrada, com a pequena grande morte em pano de fundo. Nesse sentido, a pornocultura ${ }^{34}$ que encobre nossa época não se refere apenas à esfera do erotismo, mas atravessa todas as circunstâncias em que o "eu" se perde no outro - e, ao fazê-lo, torna-se ele mesmo outro. É por isso que podemos sugerir que a "prostituição geral" da existência assinalada e temida por Marx em sua análise do modo de produção capitalista ${ }^{35}$ está hoje se impondo de maneira integral, muito além das esferas da produção e da sexualidade.

É isso que ilustram em grande detalhe, entre outros, os episódios "Natal", "Arkangel" e "Black Museum", inspirados no ritmo e na morfologia de nossas existências digitais, das redes sociais e de todas as formas de interconexão que marcam nossa vivência. A partilha ininterrupta da experiência, o estar-juntos incessante e a disponibilidade ilimitada em relação ao outro, características do reinado do always on (sempre ligado), do sharing (compartilhamento), dos followers (seguidores), dos fans (fãs), da geolocalização, mas também dos sistemas de vigilância - seu par obscuro - desenham a rendição total do indivíduo, em sua carne e espírito, a corpos estranhos.

Esta, é preciso salientar, parece ainda mais considerável na medida em que é apoiada, sem esforço particular - para usar um eufemismo - por todos aqueles que nela se envolvem com seus corações, likes, smiles, stickers, gifs e emojis entusiásticos. Embora eles mesmos suportem as consequências e sua carga correlata de sofrimento, por causa da redução de sua própria liberdade e do aumento vertiginoso

33 M. Maffesoli foi um dos primeiros pensadores a oferecer uma interpretação da cultura contemporânea baseada na metáfora dionisíaca da orgia em seu livro: L'ombre de Dionysos. Paris, Méridiens-Klincksieck, 1982.

${ }^{34}$ ATTIMONELLI, C.; SUSCA, V. Pornoculture. Voyage au bout de la chair. Montréal: Éditions Liber, 2017.

${ }^{35}$ MARX, K. Manuscritos Econômico-Filosóficos. Lisboa: Edições 70, 1989.

Dossiê A Música e suas Determinações Materiais - https://revistaecopos.eco.ufrj.br/ 
do estresse, da inquietude e da sensação de desamparo, a festa continua ${ }^{36}$. Como outrora no carnaval, essa comemoração celebra o fracasso de uma cultura, uma época e um corpo no momento em que eles sucumbem para dar espaço ao que os sucede. 0 que acontece com Lacie Pound no episódio "Queda Livre" ("Nosedive", S3E1, 2016) é sintomático nesse sentido. Em uma conjuntura em que a gratificação pessoal, o sucesso e felicidade de cada um dependem da aprovação social, mais exatamente das notas e dos votos atribuídos em tempo real pelos seus contatos, segundo o modo como atende às suas expectativas, a desastrosa aventura da protagonista indica bem que tal situação implica a coincidência paradoxal da embriaguez e do desespero, um estado que envolve a condição existencial contemporânea ao produzir uma espécie de esquizofrenia generalizada. Esse mecanismo severo incita a jovem mulher a se tornar um simulacro dela mesma, alvo de todos os tipos de humilhações e frustrações. Cada vez mais, ela mergulha em um estado de alienação e ansiedade que a torna desajeitada a ponto de perder todo o capital social a sua disposição. Privada de toda liberdade de ação, é apenas na prisão que ela encontrará um resíduo paradoxal desta liberdade - a parte amaldiçoada no ato extremo de insultar seu vizinho da célula.

A mensagem latente do episódio, um verdadeiro julgamento de nosso tempo, é tão óbvia quanto inexorável: diante de um mundo organizado segundo os princípios do controle e da avaliação, que impõe a todos a condição de liberdade monitorada, a penitenciária - concebida pelas instituições modernas como lugar por excelência de punição, de tratamento de condutas desviantes e de "normalização" da existência ${ }^{37}$ por respeito à vida civil da sociedade - agora se torna não uma gaiola, mas um tipo de reserva onde os homens podem exprimir de forma exacerbada o que lhes sobra de instinto, uma animalidade perdida e pervertida em fúria. É o último

${ }^{36}$ BERARDI, F. Tueries. Forcenés et suicidaires à l'ère du capitalisme absolu. Montréal: Lux Éditeur, 2016.

${ }^{37}$ FOUCAULT, M. Vigiar e punir: nascimento da prisão. Petrópolis: Vozes, 2009.

Dossiê A Música e suas Determinações Materiais - https://revistaecopos.eco.ufrj.br/ 
refúgio do indivíduo, o único parêntese em que ele pode se manifestar sem se importar com a apreciação dos outros. Pelo contrário, a vida coletiva, moldada por uma sólida aliança de leis neoliberais, redes sociais e técnicas de vigilância, aparece como um sistema carcerário a céu aberto do qual é preciso se liberar o quanto antes. Mas por que meios?

A terapia indicada nas temporadas realizadas entre 2011 e 2018, para além de suas diferenças, não deixa espaço para dúvidas: é urgente recusar a felicidade e o bem-estar ilusórios, as falsas alegrias efêmeras que drogam o indivíduo. 0 que os autores parecem denunciar é que estas são apenas distrações em comparação com o que realmente importa na vida: o amor, a liberdade, a razão e qualquer outro valor afastado do mercado dos prazeres e das emoções fáceis... Assim, de acordo com as interpretações fornecidas por Debord sobre a sociedade do espetáculo ${ }^{38}$, por Adorno e Horkheimer sobre a indústria cultural ${ }^{39}$, por Marcuse sobre o homem unidimensional ${ }^{40}$, por Postman sobre a distração até a morte ${ }^{41}$, por Lipovetsky sobre a felicidade paradoxal ${ }^{42}$ e por Illouz e Cabanas, que recentemente ofereceram suas críticas da happycratie ${ }^{43}$, a série de televisão condena sem apelo o modelo da vida contemporânea, associando seus sorrisos, corações e vibrações emocionais ao espectro da manipulação e da subjugação. Esse halo de bem-estar esconde na verdade um espelho negro estilhaçado, nossa vida reduzida em fragmentos indistinguíveis, inorgânicos e impotentes.

\footnotetext{
38 DEBORD, Guy. A sociedade do espetáculo. Rio de Janeiro: Contraponto, 1997.

${ }^{39}$ ADORNO, T.; HORKHEIMER, M. Dialética do Esclarecimento. Rio de Janeiro, Zahar Editores, 1985.

${ }^{40}$ MARCUSE, H. A ideologia da sociedade industrial: o homem unidimensional. Rio de Janeiro: Zahar, 1982.

41 POSTMAN, N. Se distraire à en mourir. Paris: Fayard, 2011.

42 LIPOVETSKY, G. A felicidade paradoxal: ensaios sobre a sociedade de hiperconsumo. São Paulo: Companhia das Letras, 2011.

43 CABANAS, E.; ILLOUZ, E. Happycratie - Comment l'industrie du bonheur a pris le contrôle de nos vies. Paris: Premier Parallèle, 2018.
}

Dossiê A Música e suas Determinações Materiais - https://revistaecopos.eco.ufrj.br/ 


\section{A tragédia do humanismo}

Black Mirror é a cortina de trevas que dispensa o humanismo. Seu olhar lúgubre reflete o infortúnio do homem moderno e o lamento daquilo que ele não é mais, de tudo que perdeu: a autonomia, o poder de agir sobre o outro, uma posição privilegiada no mundo, isto é, no centro, como indicou Leonardo da Vinci em 1490 em seu famoso desenho $O$ Homem Vitruviano. 0 que resta do sujeito que dominou o mundo, desde o Renascimento até as Guerras Mundiais, se encontra agora, tal como Dante na soleira do inferno, em uma floresta sombria, pois a via reta está perdida o caminho da razão, a força da razão ${ }^{44}$.

Game over.

Mas o jogo acabou de vez ou apenas atingimos um novo limiar?

A bem ver, tanto as conjunturas de Black Mirror quanto as de nossa existência comum parecem folhear um novo capítulo da história, que distinguimos à contraluz entre as sombras e reflexos do espelho que estudamos como um texto de antropologia, de sociologia e de filosofia. Nesse sentido, a série inglesa marca ao mesmo tempo o fechamento de uma época - do grego epoké, parênteses - e a abertura de uma outra. Não se trata mais, como dizia a primeira parte de 2001: Uma Odisseia no Espaço, do "alvorecer da humanidade", mas daquilo que começa a luzir após o crepúsculo do humanismo.

As auroras digitais são as luzes sarapintadas que florescem nos jogos, nas danças e nas convulsões do claro-escuro, o que está surgindo aquém e além de nós e daquilo que fomos até ao momento presente.

A mudança da ficção para realidade, de Black Mirror para nossa vida cotidiana, nos incita talvez menos a detectar ao nosso redor as ruínas daquilo que uma vez foi

${ }^{44}$ ALIGHIERI, Dante. A Divina Comédia. São Paulo: Ed. Abril, 1981.

Dossiê A Música e suas Determinações Materiais - https://revistaecopos.eco.ufrj.br/ 
do que tentar distinguir, compreender e até mesmo acompanhar a novidade que está eclodindo aí, mesmo que esta não nos agrade e nos perturbe. Para tanto, não será necessário mudar nosso ponto de vista sobre o contemporâneo, ou dito de outra maneira, descartar nosso stock of knowledge ${ }^{45}$ para viver o presente de acordo com cânones mais adequados?

Estamos ultrapassando um limiar crucial. Diversas metáforas podem explicar essa mudança de paradigma e de cultura enquanto etapa problemática: crise, apocalipse, decadência, pôr do sol, catástrofe, fim... Como sempre no campo das grandes mutações históricas, antropológicas e sociológicas, as violências, os monstros, os atos de barbárie e tudo o que pode ser reduzido ao abominável e ao obsceno entoam o movimento do passado para o futuro. É por isso que estamos todos, de certa forma, implicados enquanto espectadores e atores na visita ao Black Museum de Nish. Como ela, assistimos espantados aos efeitos perversos dos ideais e das ciências que moldaram nossa cultura, passamos por eles um após o outro, sofrendo a cada vez. Observando mais atentamente, o autor e o realizador do episódio em questão, Charlie Brooker e Colm McCarthy, primeiro nos convidam a nos identificar com a protagonista, a compartilhar sua dor, depois a segui-la e a imitar seu exemplo. Trata-se então de encarar um espetáculo ofuscante e doloroso feito de desilusões, traições e torturas. Não estamos lidando aqui com uma narrativa abstrata, mas com o que passou pelos nossos próprios corpos, paisagens e imaginários. Mais precisamente, a tragédia humana vivida pelo pai de Nish é um elo entre o destino fatal da tecnociência ocidental e o nosso, hic et nunc.

0 doutor Rolo Haynes, um neurologista sem escrúpulos, praticou experimentos tecnocientíficos em médicos e pacientes, destinados a embaçar tanto as fronteiras entre a vida e a morte quanto as que existem entre o indivíduo e o outro.

45 SCHULTZ, A. Sens commun et interprétation scientifique de l'action humaine. In: Le chercheur et le quotidien. Paris: Méridiens-Klincksieck, 1987.

Dossiê A Música e suas Determinações Materiais - https://revistaecopos.eco.ufrj.br/ 
Demitido por conduta imoral, ele inaugura um espaço de exposição consagrado a "peças autênticas de criminologia", onde a inovação científica desencadeia mutações do ser humano ao mesmo tempo em que lhe inflige dor, o violenta. As intervenções deste neo-doutor Frankenstein consistem, particularmente, na modificação do quadro psicobiológico de seus pacientes, por um lado exteriorizando sua consciência, por outro violando sua intimidade pelo implante de psicotecnologias capazes de controlar e depois alterar seus comportamentos. Nish, a jovem visitante a quem o roteiro atribuiu sintomaticamente uma pele negra, assiste consternada a esse espetáculo atroz.

O sadismo macabro das atrações cresce pouco a pouco até o ponto culminante, a última sala, onde se encontra preso e sendo torturado o holograma de Clayton Leigh, o pai da protagonista. Haynes comprou sua consciência em troca de uma quantia de dinheiro para sua família antes de sofrer, após uma sentença questionável dos magistrados, a pena de morte na cadeira elétrica. Agora constitui a atração mais excitante do museu, com uma opção suplementar: os visitantes podem se divertir dando choques de descargas elétricas na vítima e imortalizar sua dor em uma foto-souvenir personalizada.

O macabro se transforma em lúdico, a dor em obra de arte, a tortura em oferta turística, como já antecipavam a complexa punição e o calvário da protagonista de "Urso Branco" ("White Bear", S2E2): a tecnociência ocidental subiu ao nível de estética traumática espetacular. Para enunciar temas tão sensíveis, o roteiro de "Black Museum" mobiliza um poderoso arsenal de figuras, personagens e metáforas: por exemplo, os negros, sacrificados ao longo de numerosos genocídios e abusos perpetrados sobre eles pelo colonialismo; a tecnociência, promessa de emancipação que se tornou em seguida instrumento de devastação; o museu, guardião por excelência do bom, do belo e do verdadeiro, mas também agente ou meio habilitado a objetivar e catalogar a beleza, retirando-a do mundo para transformá-la em 
propaganda do poder-saber estabelecido. Essa temática prenuncia uma dupla metanarração: Black Mirror é o museu negro de nossa época e Nish, o avatar do espectador, ou seja, nós mesmos enquanto assistimos, congelados de horror, a essa feira de atrocidades ${ }^{46}$ sem precedentes.

Nish: O que são todas essas coisas?

Rolo Haynes: Autênticas peças de criminologia. Se tiver feito algo mal, provavelmente estará lá. Dê um passeio, tenha o seu tempo, veja o que te chama atenção. Se algo despertar sua curiosidade, posso lhe contar. A maioria dos objetos aqui esconde uma história suja e triste. Como o destaque do museu, ali (...) Bom, então, não tenha pressa.

Nish: Com certeza. Essas coisas parecem tecnológicas ${ }^{47}$.

0 museu, ponta de lança dos tempos modernos, é um dos lugares mais controversos da nossa cultura. Nos tempos helenísticos, sua função de isolamento, de conservação e de exposição do belo, que o separava de todo o restante, repousava no postulado de que tudo o que estava no exterior de seus muros era menos nobre do que aquilo que abrangia. Nos últimos séculos, destacou-se como o local por excelência dedicado à separação entre arte e cotidiano, o patrimônio cultural e a vida comum, as culturas superiores e inferiores. A peregrinação que o público consagra a essa instituição e a todos os seus derivados responde a um processo ambíguo, pois associam a educação das massas à sua gratificação estética, ou seja, sublimam a integração social por meio do prazer. De fato, o preço real pago pelo visitante para ingressar - não se trata aqui do bilhete de entrada - corresponde ao que ele cede de si mesmo baseando-se na ordem simbólica e física do espaço museal, submetendo-se ao paradigma político que o preside.

Aqueles que expõem a arte e os que a admiram são os polos de uma dialética

46 BALLARD, J. La Foire aux atrocités. Éditions Tristram: Auch, 2014.

47 Texto original: Nish : So what is all this stuff ? Rolo Haynes : Authentic criminological artifacts. If it did something bad, chances are it's in here. Take a look around, take your time, see what pops out at you. Anything piques your interest, I can tell you all about it. There's a sad, sick story behind most everything here. Just like our main attraction just through there. (...) Well, then, take your time. Nish : I shall. This stuff looks techy.

Dossiê A Música e suas Determinações Materiais - https://revistaecopos.eco.ufri.br/ 
permanente, onde opera a reversibilidade entre o dom da beleza pelos artistas, curadores, políticos e outros representantes do setor e o contra-dom do público em termos de adesão ao sistema que a seleciona, conserva e dispensa. De modo ainda mais marcante, a contemplação da obra promove uma rendição do observador, do corpo social, em relação ao espaço de exposição, aos seus guardiões e agentes. Uma prova de humildade da vida cotidiana diante daquilo que a transcende. Não é por acaso que a gramática das exposições exige do corpo um comportamento impecável e uma regulação rigorosa do instinto e das pulsões: silêncio, distância em relação à obra, respeito, comportamentos dignos.

No apogeu de seu funcionamento, o sistema museal vive incessantemente à custa do real, da vida nua e do cotidiano. 0 resultado de cada exposição é sempre, de certa forma, um crime perfeito.

Black Museum é o museu no estado mais sincero e paroxístico que existe. Radicaliza a missão cumprida pelos vários museus do homem do início do século $\mathrm{XX}$; expondo e catalogando as razias realizadas pelos ocidentais nos países $\operatorname{colonizados}^{48}$, ele perpetua a tradição dos freak shows e atualiza os diversos haréns coloniais ${ }^{49}$, bem como as experiências nazistas sobre corpos tratados como cobaias $^{50}$. 0 jogo estético dirigido pelo doutor Haynes cristaliza o crime perpetrado contra os subalternos para torná-los uma arma de entretenimento de massa, traduzindo a destruição em distração em seu laboratório de terror. Sua mão opera em nome da tecnociência com a cumplicidade dos dispositivos estéticos: um gesto análogo ao realizado pelas elites do sistema artístico, que arrancam a beleza dos campos onde brota e dos espaços da experiência para trancá-la nas fortalezas museais, depreciando-a em nome de sua proteção e exposição. Nos dois casos, trata-

${ }^{48}$ CLIFFORD, J. The Predicament of Culture: Twentieth Century Ethnography, Literature, and Art. Cambridge: Harvard University Press, 1988.

${ }^{49}$ ALLOULA, M. Le Harem colonial, images d'un sous-érotisme. Paris: Séguier, 2004;.

${ }^{50}$ ESPOSITO, R. Biopolitica e filosofia. Turin: Einaudi, 2004.

Dossiê A Música e suas Determinações Materiais - https://revistaecopos.eco.ufri.br/ 
se de matar e imortalizar em nome da política, da arte e do prazer. Matar e imortalizar: dois lados da mesma moeda. 0 imaginário de Black Mirror, nossa vida cotidiana.

\section{Referências bibliográficas}

ABRUZZESE, Alberto. Forme estetiche e società di massa: Arte e pubblico. Venise, FR: Marsilio, [1973] 2001.

ABRUZZESE, Alberto; MICONI Andrea. Zapping: Sociologia dell'esperienza televisiva. Naples, FL: Liguori, 1999.

ADORNO, Theodor W ; HORKHEIMER, Max. La dialectique de la raison. Paris, FR: Gallimard, [1947] 1974.

ALLOULA, Malek. Le Harem colonial, images d'un sous-érotisme. Paris, FR: Séguier, [1981] 2004.

ATTIMONELLI, Claudia; D'OTTAVIO, Angela. To be continued: I destini del corpo nei serial televisivi. Bari, IT: CaratteriMobili, 2011.

( __ . . ).; SUSCA, Vincenzo. Pornoculture : Voyage au bout de la chair. Montréal, Canada: Éditions Liber, [2016] 2017.

BARDIN, Laurence. L'analyse de contenu. Paris, FR: PUF, [1977] 2013.

BAUDRILLARD, Jean. À l'ombre des majorités silencieuses ou la fin du social. Paris, FR: Sens \& Tonka, [1977] 1997.

(___. ).. Simulacres et simulations. Paris, FR: Galilée, 1981.

(__ . ).. L'esprit du terrorisme. Paris, FR : Galilée, 2002.

BENJAMIN, Walter, Aura e choc : Saggi sulla teoria dei media. Turin, IT: Einaudi, 2012.

BENNATO, Davide (dir. par). Black Mirror. Distopia e antropologia digitale. Catane, IT: Villaggio Maori, 2018.

Dossiê A Música e suas Determinações Materiais - https://revistaecopos.eco.ufrj.br/

ISSN $2175-8689$ - v. 23, n. 1, 2020

DOI: 10.29146/eco-pos.v23i1.27406 
BERARDI, Franco. Tueries. Forcenés et suicidaires à l'ère du capitalisme absolu. Montréal, CA: Lux Éditeur, 2016.

BRANCATO, Sergio. Post-serialità: per una sociologia delle tv-series. Dinamiche di trasformazione della fiction televisiva. Naples, IT: Liguori, 2011.

CABANAS, Edgar; ILLOUZ, Eva. Happycratie: Comment l'industrie du bonheur a pris le contrôle de nos vies. Paris, FR : Premier Parallèle, 2018.

CARDON, Dominique. À quoi rêvent les algorithmes : Nos vies à l'heure des big data. Paris, FR : Seuil, 2015.

CASILLI, Antonio A., Les liaisons numériques. Paris, FR : Seuil, 2010.

CASTELLS, Manuel. L’Ère de l'information : Vol. 1, La Société en réseaux. Paris, FR: Fayard, 1998.

CHIUSI Fabio. Dittature dell'istantaneo: Black Mirror e la nostra società iperconnessa. Turin, IT : Codice Edizioni, 2014.

CIRUCCI, Angela M; VACKER, Barry (dir. par). Black Mirror and Critical Media Theory. Lanham, EUA: Lexington Books, 2018.

CLIFFORD, James W. The Predicament of Culture: Twentieth Century Ethnography, Literature, and Art. Cambridge, UK: Harvard University Press, 1988.

DE KERCKHOVE, Derrick. La peau de la culture. Montréal, CA : Éditions Liber, [1995] 2020.

(___ . ). L'inconscio digitale. In: BUFFARDI, Annalisa, DE KERCKHOVE, Derrick (dir. par). Il sapere digitale. Pensiero ipertestuale e conoscenza connettiva. Naples, IT: Liguori, 2011.

(__ . ). The point of being. In: DE KERCKHOVE, Derrick, MIRANDA, Cristina (dir. par). The point of being. New Castle Upon Tyne, UK: Cambridge Scholars Publishing, 2014.

DE MICHELI, Mario. Le avanguardie artistiche del Novecento. Milan, IT: Feltrinelli, 2014.

DEBORD, Guy. La Société du spectacle. Paris, FR : Gallimard, [1967] 1992.

DESCARTES, René. Discours de la méthode. Paris, FR : Flammarion, [1637] 2010.

DURAND, Gilbert Les structures anthropologiques de l'imaginaire. Paris, FR: Dunod, [1960] 1992.

ESPOSITO, Roberto. Bios. Biopolitica e filosofia. Turin, IT: Einaudi, 2004.

Dossiê A Música e suas Determinações Materiais - https://revistaecopos.eco.ufrj.br/

ISSN $2175-8689$ - v. 23, n. 1, 2020

DOI: 10.29146/eco-pos.v23i1.27406 
FERRARIS, Maurizio. T'es où ?: Ontologie du téléphone mobile. Paris, FR : Albin Michel, [2005] 2011.

FOUCAULT, Michel. Surveiller et punir : La naissance de la prison. Paris, FR : Gallimard, 1975.

FUKUYAMA, Francis. La Fin de l'histoire et le Dernier Homme. Paris, FR : Flammarion, 1992.

GRASSI, Valentina. Introduction à la sociologie de l'imaginaire. Paris, FR : Erès, 2005.

GUILHAUMOU, J. Le corpus en analyse du discours : perspective historique. Corpus, n. 1, 2002.

HEIDEGGER, Martin. Lettre sur l'humanisme. Paris, FR : Éditions Montaigne, [1946] 1957.

(__ . ). Acheminement vers la parole. Paris, FR: Gallimard, [1959] 1976.

HOLMES, Oliver W. The Stereoscope and the Stereograph. In: NEWHALL, Beaumont. Photography: Essay and Images. New York, NY: The Museum of Modern Art, [1869] 1980.

INNIS, Harold A. Empire and Communications. Toronto, CA: Dundurn, [1950] 2007.

INNOCENTI, Veronica; PESCATORE, Guglielmo. Le nuove forme della serialità televisiva: Storie, linguaggio, temi. Bologne, IT: Archetipo Libri, 2008.

JENKINS, Henry. Fans, bloggers, gamers. Exploring participatory culture. New York, NY: New York Press, 2006.

JORON, Philippe. La vie improductive. Georges Bataille et l'hétérologie sociologique. Montpellier, FR: Presses Universitaires de la Méditerranée, 2009.

LA ROCCA, Fabio; MALAGAMBA, Antoni0; SUSCA, Vincenzo (dir. par). Eroi del quotidiano. Figure della serialità televisiva. Milan, IT: Bevivino, 2010.

LEGROS, Patrick, MONNEYRON; Frédéric, RENARD; Jean-Brun; TACUSSEL, Patrick. Sociologie de l'imaginaire. Paris, FR: Armand Colin, 2006.

Les Cahiers européens de l'imaginaire. Technomagie, nº 3. Paris : CNRS Éditions, 2011.

LIPOVETSKY, Gilles. Le bonheur paradoxal: Essai sur la société d'hyperconsommation. Paris, FR: Gallimard, 2006.

LOVINK, Geert. Networks without a Cause: A Critique of Social Media. Londres, UK: Polity Press, 2012.

Dossiê A Música e suas Determinações Materiais - https://revistaecopos.eco.ufrj.br/

ISSN $2175-8689$ - v. 23, n. 1, 2020

DOI: 10.29146/eco-pos.v23i1.27406 
MAFFESOLI, Michel. L'ombre de Dionysos. Contribution à une sociologie de l'orgie. Paris, FR: Méridiens-Klincksieck, 1982.

(___. . Le temps des tribus : Le déclin de l'individualisme dans les sociétés de masse. Paris, FR: Méridiens-Klincksieck, 1988.

(___. ). Notes sur la postmodernité : Le lieu fait lien. Paris, FR : Éditions du Félin, 2003.

(___. ). Le réenchantement du monde. Paris, FR : La Table Ronde, 2007.

MARCUSE, Herbert. L'homme unidimensionnel. Paris, FR: Les Éditions de Minuit, [1964] 1968.

MARX, Karl. Manuscrits de 1844 : Économie politique et philosophie. Paris, FR: Éditions Sociales, [1844] 1972.

MATTELART, Armand. La Communication-monde. Paris, FR : La Découverte, [1992] 1999.

MCLUHAN, Marshall H. The Gutenberg Galaxy: The making of typographic man. Toronto, CA : University of Toronto Press, [1962] 1966.

(___. ). Pour comprendre les médias. Québec, CA : Bibliothèque Québécoise, [1964] 1993.

NANCY, Jean-Luc. Sexistence. Paris, FR: Galilée, 2017.

PASCAL, Blanchard et al. Sexe, race \& colonies. La domination des corps du XVème siècle à nos jours. Paris, FR: La Découverte, 2018.

PARISEAU-LEGAULT, Pierre ; HOLMES, Dave ; MURRAY, Stuart J. Understanding human enhancement technologies through critical phenomenology. Irvine (Californie): Nursing Philosophy, 2018.

PERNIOLA, Mario. Le sex-appeal de l'inorganique. Paris, FR: Léo Scheer, [1994] 2003.

PIREDDU, Mario. Algoritmi : Il software culturale che regge le nostre vite. Bologne, IT: Luca Sossella Editore, 2017.

PIREDDU, Mario; TURSI, Antonio (dir. par). Post-umano. Milan, IT: Guerini \& Associati, 2006.

POSTMAN, Neil. Se distraire à en mourir. Paris, FR : Fayard, [1985] 2011.

RAFELE, Antonio. La Métropole : Benjamin et Simmel. Paris, FR: CNRS Éditions, 2010.

Dossiê A Música e suas Determinações Materiais - https://revistaecopos.eco.ufrj.br/

ISSN $2175-8689$ - v. 23, n. 1, 2020

DOI: 10.29146/eco-pos.v23i1.27406 
RIEFFEL, Rémy. Sociologie des médias. Paris, FR: Ellipses, 2001.

SADIN, Éric. La vie algorithmique : critique de la raison numérique. Paris, FR: Éditions l'Échappée, 2015.

SCHÜTZ, Alfred. Sens commun et interprétation scientifique de l'action humaine. In : Le chercheur et le quotidien. Paris, FR: Méridiens-Klincksieck, [1953] 1987.

SUSCA, Vincenzo. Récréations: Galaxies de l'imaginaire postmoderne. Paris, FR: CNRS Éditions, [2008] 2009.

(___. ). Joie Tragique. Les formes élémentaires de la vie électronique. Paris, FR : CNRS Éditions, [2010] 2011.

(__ . ). Les Affinités connectives : Sociologie de la culture numérique. Paris, FR: Cerf, 2016.

(__ . ).Esperienza. In: TIRINO, Mario, TRAMONTANA, Antonio (dir. par). I riflessi di Black Mirror, Glossario su immaginari, culture e media della società digitale. Rome, IT: Rogas Edizioni, 2018.

TIRINO, Mario; TRAMONTANA, Antonio (dir. par). I riflessi di Black Mirror, Glossario su immaginari, culture e media della società digitale. Rome, IT: Rogas Edizioni, 2018.

VATTIMO, Gianni. La società trasparente. Milan, IT: Garzanti, 1989.

VIDAL, Bertrand. Les représentations collectives de l'événement-catastrophe: étude sociologique sur les peurs contemporaines. (Dir. par) TACUSSEL, Patrick. Montpellier, CA: Lersem-Irsa, Université Paul-Valéry, 2012.

WEBER, Max. L'éthique protestante et l'esprit du capitalisme. Paris, FR: Plon, [1904] 1964.

WILLIAMS, Raymond. Television: technology and cultural form. Londres, UK: Routledge, 2003.

XIBERRAS, Martine. Pratique de l'imaginaire. Laval, CA: Pul, 2002.

\section{Literatura de ficção}

ALIGHIERI, Dante. L’Enfer, La Divine comédie. Paris, FR: Flammarion, [1472] 1985.

BALLARD, James G. La Foire aux atrocités. Auch, FR : Éditions Tristram, [1976] 2014.

Dossiê A Música e suas Determinações Materiais - https://revistaecopos.eco.ufrj.br/

ISSN $2175-8689$ - v. 23, n. 1, 2020

DOI: 10.29146/eco-pos.v23i1.27406 
BALZAC, Honoré. Splendeurs et misères des courtisanes. Paris, FR : Gallimard, [1838-1847] 1973.

SHELLEY, Mary. Frankenstein. Paris, FR: Gallimard, [1818] 1992.

STOKER, Bram. Dracula. Paris, FR: J'ai Lu, [1897] 2012.

\section{Filmografia}

2001: A Space Odyssey (2001: L'Odyssée de l'espace). KUBRICK, Stanley. 1968, ÉtatsUnis/ Royaume-Uni.

La Sortie de l'usine Lumières. LUMIERE, Auguste, LUMIERE, Louis,1895, France.

Metropolis. LANG, Fritz, 1927, Allemagne.

Modern Times (Les Temps Modernes). CHAPLIN, Charlie, 1936, États-Unis. 